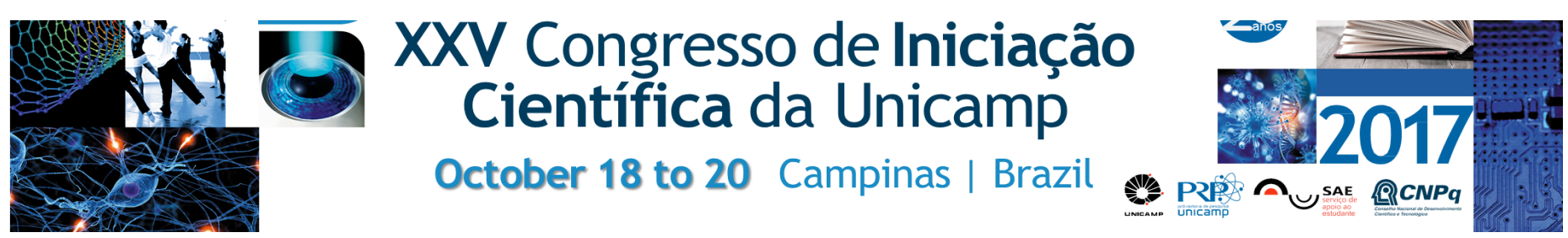

\title{
Argon Plasma Effect on Bond Strength of Bulk-fill Composite Repair
}

\section{Beatriz C. Mendonça, Bruna M. Fronza, Gabriel Nima, Gláucia M. B. Ambrosano, Marcelo Giannini}

\begin{abstract}
This study evaluated the effect of atmospheric pressure plasma (PL), sandblasting with aluminum oxide (SA), and the on the bond strength of fresh bulk-fill resin composite to water-aged restorative bulk-fill resin composite. Seventy prepolymerized composite plates were fabricated using Filtek Bulk Fill Posterior Restorative (3M ESPE) stored in distilled water for 4 months and randomly divided into 4 groups. For all specimen, two resin cylinders were made using a 1,4 mm diameter $\times 1 \mathrm{~mm}$ height matrix. The resin cylinders were tested after 24 hours, using shear test device. Data were analyzed by 2-way ANOVA and Tukey's test (5\%).
\end{abstract}

Key words: Composite Resin, Repair, Plasma, Bond Strength.

\section{Introduction}

A possible alternative to improve adhesion between old and new composites would be the application of plasma generated from argon gas. Plasma acts by changing the functional groups on different treated surfaces to transform an inactive (nonpolar) material into a reactive (polar) one, without structural properties changes.(1)

Plasma has already been used in indirect restorations, more specifically in zirconia structures (2) and also in adhesion to dentin (3), but limited information are available regarding composite repair.

\section{Results and Discussion}

Seventy pre-polymerized composite plates (15 $\mathrm{mm}$ long $\times 8 \mathrm{~mm}$ wide $\times 3 \mathrm{~mm}$ thick) were fabricated using Filtek Bulk Fill Posterior Restorative (3M ESPE) and stored in distilled water for 4 months. The aged plates were polished with 600-grit SiC paper and assigned to the following groups:

\begin{tabular}{|l|l|}
\hline Group 1 & SA $(50 \mu \mathrm{m})$ for 10 seconds, \\
\hline Group 2 & PL for 30 seconds \\
\hline Group 3 & $\begin{array}{l}\text { SA }(50 \mu \mathrm{m}) \text { for } 10 \text { seconds + PL for } \\
30 \text { seconds and }\end{array}$ \\
\hline Group 4 & $\begin{array}{l}\text { SA }(50 \mu \mathrm{m}) \text { for 10 seconds + silane + } \\
\text { hydrophobic adhesive resin (control). }\end{array}$ \\
\hline
\end{tabular}

After treatments, a silicone mold was used to construct a bulk-fill composite resin cylinder $(1.5 \mathrm{~mm}$ high, $1.5 \mathrm{~mm}$ diameter) on each aged composite plate. Following water storage for 24 hours, samples were submitted to shear bond testing. Data were expressed in MPa $(n=6)$ and statistically analyzed by one-way ANOVA and Tukey test $(\alpha=0.05)$.
Table 1. Mean (standard deviation) of bond strengths for experimental groups (in MPa).

\begin{tabular}{|c|c|c|}
\hline Treatment & Mean & $\begin{array}{c}\text { Standard } \\
\text { Deviation }\end{array}$ \\
\hline $\begin{array}{c}\text { SA with Aluminium Oxide } \\
\text { (50 } \mu \text { ) for } 10 \mathrm{~s}\end{array}$ & $7.0 \mathrm{~b}$ & 2.3 \\
\hline PL for $30 \mathrm{~s}$ & $4.6 \mathrm{c}$ & 1.8 \\
\hline SA + PL & $5.6 \mathrm{bc}$ & 1.2 \\
\hline $\begin{array}{c}\text { SA + Silane + Hydrophobic } \\
\text { adhesive resin (control) }\end{array}$ & $18.1 \mathrm{a}$ & 2.2 \\
\hline \begin{tabular}{c} 
Means followed by distinct letters differ from each other $(p \leq 0.05)$ \\
\hline
\end{tabular}
\end{tabular}

\section{Results}

Sandblasting followed by application of silane and hydrophobic resin showed the highest bond strength.

Only plasma application for 30 seconds showed the lowest bond strength compared to other types of surface treatments.

Sandblasting followed by plasma application for 30 seconds did not differ statistically from the following treatments: sandblasting with aluminum oxide for 10 seconds and applying plasma for 30 seconds.

\section{Conclusion}

The conventional method to repair composites that included sandblasting, silane and hydrophobic adhesive resin yielded the highest bond strength of fresh bulk-fill composite to water-aged bulk-fill resin composite. Plasma alone and its combination with sandblasting were not beneficial as control.

\section{Acknowledgement}

\section{Support by SAE - UNICAMP}

1. Duan YX, Huang C, Yu QS. Cold plasma brush generated at atmospheric pressure. Review of Scientific Instruments.2007; 78:2732.

2. Lopes BB, Ayres APA, Lopes LB, Negreiros WM, Giannini M. The effect of atmospheric plasma treatment of dental zirconia ceramics on the contact angle of water. ApplAdhesionSci. 2014, May;2(7):1-8.

3. Hirata R, Teixeira H, Ayres AP, Machado LS, Coelho PG, Thompson VP, Giannini M. Long-term Adhesion Study of Self-etching Systems to Plasma-treated Dentin. J Adhes Dent. 2015 Jun;17(3):227-33. 